\title{
LA REVISTA GERMINAL, CRISOL DE ESTÉTICAS
}

\author{
DOLORES THION SORIANO-MOLLÁ \\ dolores.thion@univ-pau.fr \\ Université de Pau et des Pays de l'Adour
}

\section{Resumen}

La «Gente Nueva» que constituyó el Grupo Germinal en 1897 fundó una de las revistas culturales pioneras en el Fin de Siglo, Germinal. Su objetivo era aglutinar a intelectuales y artistas en aras a la reforma de España. Sus páginas, por lo tanto, fueron un crisol de las sensibilidades y estéticas que convivieron en aquellos tumultuosos años de finales del siglo XIX y principios del XX.

Palabras clave: Germinal, Periodismo cultural, Revistas ilustradas, Gente Nueva, Modernismo, Naturalismo, Decadentismo, Esteticismo.

\begin{abstract}
The «New People» which was the Germinal Group in 1897 founded a pioneering cultural magazines in the Fin de Siglo, Germinal. His goal was to bring together intellectuals and artists in order to reform Spain. Germinal's pages, therefore, were a melting pot of sensibilities and aesthetics who lived in those tumultuous years of the late nineteenth and early twentieth centuries.
\end{abstract}

Keywords: Germinal, cultural journalism, Magazines illustrated, New People, Modernism, Naturalism, Decadence, Aestheticism.

Los estudios sobre la prensa cultural del Fin de Siglo reconocen de manera unánime el carácter pionero de las revistas que fue fundando el Grupo Germinal y la labor que realizaron para la difusión de nuevas estéticas y de creaciones literarias de autores, en su mayoría, comprometidos con la regeneración de España. Sus colaboradores eran aquellos escritores que, por rebeldía y por necesidad de autoafirmación, empezaron a agruparse a partir de 1890 en

Anales, 26, 2014, pp. 499-519

DOI: 10.14198/ALEUA.2014.26.21 
torno a la Agrupación Demócrata-Social y su periódico La Democracia Social (1895); en torno a la bandera de Germinal y sus homónimas revistas de 1897 a 1903, así como en Vida Nueva, en Don Quijote y en los periódicos El País y El Progreso; en las esferas del republicanismo radical. Las circunstancias políticas, el desarrollo del sector editorial, el abaratamiento del libro, las traducciones, el teatro y el periódico son algunas de las causas que estimularon a aquellos jóvenes a participar en los movimientos sociales de la época y a contribuir al desarrollo de la cultura finisecular. Más que de una Edad de Plata, convendría recordar aquel marbete de la Edad de Oro Liberal o Segunda Edad de Oro de las Letras Españolas.

«Primero opinión, luego quejido, más tarde lucha» (Thion, 1999) fueron las voces y actitudes de aquellos futuros germinalistas que llegaron al centrípeto Madrid de las últimas décadas del siglo XIX. Llegaron ávidos de una ideal y de una seductora vida intelectual y artística, de respirar los nuevos aires europeizantes y de participar apasionadamente en los conflictos sociales e ideológicos de aquella España en profunda crisis. Eran jóvenes pertenecientes a la pequeña burguesía, en su mayoría autodidactas, para quienes el signo de dicha juventud no era sino la del espíritu o del alma, por lo que fueron aglutinando a todos aquellos que apostaban por lo nuevo y por la moderno en todos los ámbitos frente al pasado, a la tradición, a lo heredado, al poder y a la burguesía. Bajo la etiqueta de la Gente nueva o joven -sin distinciones de edad- pero como frente de oposición a la Gente vieja, se fueron agrupando personalidades de muy distinto cariz, escritores, periodistas, intelectuales, científicos, krausistas... gran parte de ellos reformistas, rebeldes y bohemios empeñados en definir un espacio político, artístico y cultural autónomo, un espacio disyuntivo en el que se exhibía una modernidad ideológica o un modernismo estético no sólo para autoafirmarse, sino también para afirmarse contra todo lo adquirido o instaurado. Esa Gente nueva tomó el nombre de Germinal, propuesto por Bark, recordando el símbolo del cuarto evangelio zolesco como símbolo aglutinador.

El viernes 30 de abril de 1897 salía a la luz el primer número del semanario Germinal, con ocho páginas al precio de quince céntimos, lo que lo ubicaba entre los productos culturales de consumo esencialmente mesocrático. Tras un mes de existencia y fortalecimiento material pasó a subtitularse Revista semanal ilustrada y aumentó sus páginas a doce. Las primeras se consagraban a temas doctrinales y socio-políticos, en las siguientes predominaban los temas culturales y artísticos, junto con reseñas bibliográficas y teatrales.

Como director figuraba el cabeza de grupo Joaquín Dicenta, hasta octubre de 1897, le sucedió Nicolás Salmerón y García, hasta diciembre de aquel 
año y, en 1901, el anarquista Eduardo Barriobero en las dos últimas salidas de la revista, en 1901 y en 1903. El consejo de redacción estaba formado por Francisco Maceín y A. de Santaclara (Bark). Los corresponsales eran Isidoro López Lapuya, en París, y C. Von Werner, en Berlín. Los redactores eran los siguientes: Rafael Delorme, Ricardo Fuente, José Jurado de la Parra, Antonio Palomero, Manuel Paso, Nicolás Salmerón y García y Eduardo Zamacois. Entre los colaboradores hemos de destacar a Alfredo Calderón, Urbano González Serrano, Jacinto Octavio Picón, Jacinto Benavente, Isidoro López Lapuya, Ramiro de Maeztu, Mariano de Cavia, Eusebio Blasco, Arturo Reyes, José Juan Cadenas, Julio Burell, Antonio Montilla, Ricardo Catarineu, Antonio Zozaya, José Verdes Montenegro, Alejandro Sawa, Ciro Bayo, etc. Se trata de una lista heterogénea de publicistas que convergieron en la denuncia y en la búsqueda de nuevos derroteros en las encrucijadas de una sociedad en transición.

Germinal se proponía actualizar los idearios republicanos y acercarlos al socialismo, unir frentes y estrechar relaciones con el pueblo:

GERMINAL es un periódico que representa la más avanzada trinchera de juventud progresiva en nuestra patria, y, por lo tanto, tiene un criterio amplísimo en materia de Socialismo, puesto que en su redacción existen no pocos partidarios del ideal acrático. [...] hemos venido al estadio de la prensa a defender con valentía y precisión las ideas socialistas todas, desde el Socialismo humanitario al que profesa el poeta sentimental, desde el Socialismo marxista hasta los ideales de la autonomía individual y de la extinción de toda opresión autoritaria.... («Profesión de fe», 6-VIII-1897, págs.1-2)

Siempre se definió, resumía Francisco Maceín, como un seminario que pretendía ser «el eco de los trabajadores honrados y el reflejo de todas las aspiraciones revolucionarias, vengan de donde vengan y expóngalas quien las exponga, ¡una tribuna amplia, expansiva, radical, enemiga de todo lo que signifique autoritarismo, completamente libertaria!» (Maceín, 24-III-1899, pág. 4). Lo que les reunía era el deseo de ruptura respecto de un pasado referencial y los anhelos de la modernidad. Bajo lo nuevo o moderno y en contra de lo instaurado cabía un amplio elenco de posibilidades y perspectivas, las cuales comparten una misma actitud política y ética, la crítica a la Restauración, el rechazo de los valores burgueses dominantes, la disidencia frente a las ideas y creencias imperantes, la rebelión frente al poder -político y religioso- y la ruptura frente a la tradición; «en política la República como punto de arranque, la República Social como fin inmediato y el progreso indefinido como ideal supremo», pero asimismo, «la libertad para el pensamiento en el libro, en la tribuna, en el teatro, en el arte, en todo» («Germinal», 24-V-1897, pág. 1). 
Germinal creyó sobre todo en el poder de la palabra, en la necesidad urgente de la educación y de la transformación de las mentalidades. Su quehacer pudo parecer vago quejido, pero contribuyó a través de la propaganda a sensibilizar las mentalidades como grupo de presión en contra del sistema vigente, en particular, del bipartidismo, del caciquismo, de la corrupción, del endeudamiento, de las guerras coloniales, del clericalismo, de la concentración de capitales y la consiguientes inequidad e injusticia sociales. Porque el rechazo y de la rebelión encarnaron la actitud vital y el estado espiritual del grupo Germinal, e hicieron de lo nuevo o de lo moderno su bastión, dichos atributos también caracterizaron sus voces, sus verbos y su capacidades críticas y creativas. Por ello, en Germinal la literatura ostentó un rango preferencial entre las actividades literarias, no sólo por desenvolverse en un medio material idóneo para su divulgación, sino también por haber adquirido nuevas funciones y valores asimilados al proceso de regeneración nacional. Los artículos sobre crítica literaria estaban firmados principalmente por Urbano González Serrano, Ricardo Fuente, Enrique Alonso y Orera, Ernesto Bark, Eduardo Zamacois, Jacinto Benavente, Antonio Palomero, Joaquín Dicenta y Francisco Maceín. Dichos artículos no ocupaban una sección fija con título establecido. Aparecían entremezclados con las composiciones poéticas y narrativas y los artículos científico-culturales sin orden preestablecido. Por razones de espacio, dedicaremos ahora a los aspectos críticos fundamentales que animaron a los escritores germinalistas a promover un uso socio-político de la literatura en su primera revista Germinal y la absorción de todas las tendencias estéticas finiseculares.

\section{Función social y estética de la literatura}

Subversión, rebeldía, denuncia social, utilitarismo, propaganda, educación y goce estético constituyen de entrada las principales características del arte y pensamiento literarios en Germinal. Albergue de multiplicidad de tendencias, de multitud de autores reconocidos, disidentes y marginales; la redacción de Germinal quiso adoptar nuevos e incluso divergentes derroteros para el arte. En estas páginas observaremos cómo la primacía de lo social o la de lo estético en el arte no estaban reñidas, sino que constituían un binomio de fuerzas claves en el devenir de la literatura en España. La rebeldía política de la Gente nueva se materializó en el arte en el rechazo de los códigos y producciones burgueses. Desde Germinal, pretendían erradicar ese:

arte rutinario con fiscales que lo denuncian en el libro, cómicos que lo rebajan en el teatro, obispos que lo sujetan a leyes crónicas desde el público, y críticos que lo estacan en un pantano de discusiones y de amaneramientos 
académicos [...] una dictadura artística que chochea y produce náuseas en el cerebro. Eso ha encontrado Germinal y contra todo eso se revuelve ( $G$ Germinal», 24-V-1897, pág. 1).

Les respaldaba la creencia en el poder performativo y catalizador de arte en el proceso de revolución social; lo cual, les amparaba en sus intentos de crear un espacio literario propio frente al arte consagrado, de convertir el discurso estético en propaganda capaz de incitar a la acción y al cambio. Si políticamente los germinalistas se habían definido como grupo abierto a todos aquellos que luchaban desde distintas facciones por el progreso, cada uno con sus medios y circunstancias, en el terreno del arte también rigieron los mismos principios. Merced a la amplitud de corrientes abarcadas y al pluralismo del grupo, Germinal abrió las puertas de su redacción a todo aquel que quisiera contribuir en su proyecto regenerador. Según escribía Dicenta en Germinal cabían:

todos, los literatos revolucionarios con sus poemas, con sus artículos, con sus versos; los pintores con sus cuadros; los escultores con sus estatuas; los músicos con sus notas, los hombres de ciencia con sus números, con sus sistemas, con sus descubrimientos, los socialistas de diversas escuelas, desde la más conservadora a la más radical, con su credo y con sus energías. Todo el que grite ¡Adelante! está dentro de Germinal. Todo el que diga ¡Basta! ¡Atrás!; está fuera de él. [...] Todos caben en Germinal porque todas dan frente al porvenir (Dicenta, 17-IX-1897, pág. 2).

En Germinal, el arte representaba una herramienta para la propaganda y la educación, siguiendo los tradicionales usos pragmáticos de la literatura y el tópico horaciano del enseñar deleitando, con el cual, pensaban transmitir conocimientos y educar sensiblemente; o sea, preparar a nuevos ciudadanos, hombres equilibrados y libres, para una España moderna. Esta era una de las claves, según los germinalistas, para la revitalización de la sociedad. A través del deleite y goce artísticos se podían dar a conocer las lacras y vicios de la sociedad, y se podían enseñar, mediante adoctrinamientos sutiles, los paliativos que el republicanismo socialista proponía. Con estos presupuestos y al igual que ocurría en política, los artistas en Germinal, recordaba Ricardo Fuente:

Viven en continua guerra con las opiniones de su época y forman siempre en la vanguardia de la revolución. Ahora son poetas de los pobres, trovadores de los desheredados, y van sembrando la semilla para que recojan el fruto los legisladores del porvenir. Este apostolado también tiene su calvario porque la sociedad aún santifica a los innovadores... Las ideas nuevas no pueden aprenderse en España en los libros de ciencia, porque no los hay, ni en las Universidades, porque no enseñan; sólo el arte puede propagarlas (Fuente, 1897, págs. 55-57). 
Como pone de manifiesto el testimonio de Fuente, el denominador común de aquellos polifacéticos germinalistas era el considerarse los apóstoles destinados a la sublime misión de la regeneración nacional. Todos aclamaban el conjunto de ideas y valores nuevos que posibilitasen el establecimiento de España dentro del círculo europeo y conciliasen la escisión que entre nuestra nación y Europa existía. Basta con leer los titulares de sus artículos para percibir sus gritos de protesta: "Cómo se lucha», «La vuelta de las cigüeñas», «El arte en las Cámaras», «El cliché», «Decadencia crítica», «El renacimiento literario», «El arte y la gente honrada», por citar algunos ejemplos elocuentes, de lo que luego consideró el mismo Zamacois, como una juvenil ceguera ante el ideal. Habían olvidado «el sabio adagio, del dicho al hecho hay mucho trecho, y creímos que la revolución española, la revolución definitiva que será la republicana socialista, podía hacerse tocando a somatén en discursos grandilocuentes y artículos incendiarios. Así lo creía el público, y nosotros reflejamos la opinión general, cohibidos por la presión sugestiva del medio» (Zamacois, 23-VII-1897, pág. 7). Fueron apasionamientos y revueltas de corte romántico, unos sueños de literatura incendiaria que sin soluciones positivas, sin programas pensados y organizados. Para la oposición fueron unos vocingleros, ya que su acción se redujo en gran medida a la denuncia en la prensa. No obstante, aún así, Germinal contribuyó a ir haciendo cambiar las mentalidades, lo cual, no era poco. «El arte, la ciencia y la literatura se transforman y rejuvenecen anunciándose como heraldos de una civilización equitativa», escribía Fraguas (14-VI-1897, págs. 6). Por ello, estetizaron lo político y lo social y, a su vez, la política y la sociedad se estetizaron en las páginas de Germinal. La polarización entre literatura escindida como representación de la realidad objetiva o como nueva realidad estética no existió en las páginas de las tribunas de Germinal

\section{El Naturalismo social}

Guiados por el afán de disidencia, el Naturalismo de Germinal, ubicado en la trayectoria final de dicho movimiento, era un Naturalismo dreyfusiano, contestatario y socialista. La Gente nueva solía denominarlo Naturalismo social o Realismo social, para distinguirlo del Realismo y del Naturalismo vigentes. Otros membretes como Naturalismo radical en oposición a Naturalismo espiritualista eran también comunes.

Los germinalistas, defensores a ultranza del cientificismo zolesco, creyeron llegada su hora, la del verdadero germinar, por observación y experimentación y con fidelidad a aquellas leyes científicas entonces consideradas infalibles, absolutas y exactas. Jacinto Benavente y Ernesto Bark proclamaban 
que el Naturalismo, merced al desarrollo de la metodología científica, era un arte grandioso, puro y eterno; el arte del buen sentido por ser verdadero documento histórico del siglo XIX (Benavente, 30-VII-1897; Bark, 10-IX-1897). José Verdes Montenegro, como tantos otros críticos literarios que siguieron a Taine, confiaba ingenuamente en la capacidad del arte como fiel espejo de la historia y lo confundieron con un documento real (Verdes, 17-XII-1897). Los germinalistas se obstinaron en proclamar que había que canalizar a través de la creación artística tanto la denuncia de los problemas y lacras sociales como el planteamiento de soluciones regeneracionistas. Esto explica que el Naturalismo social quedase convertido en estudios sociológicos o de literatura negra que respondían al estado de degeneración nacional. Como aducía Bark, al tomar como modelo las novelas del maestro francés «Zola ha dicho terminantemente que sus obras no son obras de fantasía escritas para deleitar, son estudios sociológicos, reconstrucciones de la vida que están basados en documentos humanos» (Bark, 10-IX-1897, pág.1). Para la configuración de dichos documentos humanos, cientificismo y socialismo humanista caminaban a la par, y, merced a ellos, los germinalistas documentaron experimentalmente la decadencia del hombre del siglo XIX. En sus estudios literarios, siguiendo las orientaciones del naturalismo francés, quisieron demostrar que el hombre era resultado de la selección natural, si bien, en la práctica, unos se decantaron por el determinismo biológico y otros prefirieron el determinismo ambiental. Lo fundamental era presentar al hombre en su contexto, con sus particulares comportamientos y sentimientos. Eligieron para ello a los más en sus ambientes tétricos y paupérrimos, bajo las convulsiones del dolor, de la miseria y de la inmundicia, sin que hubiese lugar para la resignación y para la compasión religiosas con las que las esferas del poder acallaban a las masas.

En lo que respecta al estilo naturalista, en Germinal se insistió en la exhaustividad de las descripciones, en las que tanto importaba el detalle accidental como el característico, y en la adecuación y naturalidad del lenguaje para reflejar fielmente las capas más bajas y marginales de la sociedad. La terrible miseria, la tristeza, el dolor, la degeneración y los crímenes que presentan estos dramáticos estudios sociales exigían un lenguaje «valiente» que tenía que convertirse en el grito arrollador de la revolución social (Bark, 20-IX-1897, pág. 9). En definitiva, nuestros publicistas insistieron en los aspectos deterministas y políticos del naturalismo contribuyendo a acuñar el marbete de naturalismo socialista o radical. Desde Germinal se erigió a Joaquín Dicenta en su pionero. Merced a Juan José se le concedió unánimemente la categoría de portaestandarte del naturalismo en España. Bark justificaba tal elección por el hecho de ser considerado el primer escritor que recogía 
fielmente los presupuestos de la escuela estética de Zola, de modo que a diferencia de otros países, el naturalismo en España había nacido en los dramas sociales de Dicenta. Ese mismo naturalismo no alcanzó el éxito en la novela en los términos que Bark lo entendía: ateo-determinista y socialista-revolucionario. Consideraba a Alejandro Sawa como a su único representante a pesar del vigor del novelista en Crimen Legal, del «grito de desesperación» del luchador que se asfixia en Declaraciones de un vencido, y del cuadro lúgubre de la sociedad sumergida en «tinieblas seculares» de Noche. Para Bark, en realidad, Sawa no era tan desgarrador, frío y duro como un cuadro sociológico de un Naturalismo social radical lo requería. Por otra parte, Bark fue orientando sus opiniones en función de las críticas y polémicas que Sawa suscitaba en la oposición. Unas veces presentaba a un Sawa un tanto laxista, que como buen español y respondiendo al determinismo de raza, estaba abocado a ser «un alma profundamente poética» $y$, sus novelas, a estar impregnadas de tintes románticos, costumbristas y populares. Otras, empero, cuando Alejandro Sawa era juzgado negativamente por el «opusculum» literario, Bark acudía en su defensa y refutaba las acusaciones de exageración en el estilo que recaían sobre su amigo. Aducía entonces el crítico estonio: «La obra de Sawa es sobre todo una protesta contra la hipocresía reinante y su estilo se asemeja a la oratoria guerrera de un Napoleón I, y le faltan los tintes finos que acompañan las descripciones delicadas y que no deben buscarse en esta clase de literatura militar» (Bark, 10-IX-1897, pág. 1). No obstante, la definición de un naturalismo a partir del grado de protesta, dureza y virilidad empleados para la representación de la sociedad son parámetros poco consistentes; a sabiendas que el propio Zola no excluyó muchos elementos de carácter romántico, tales como la simbolización de la sociedad, la animalización e incluso mineralización del hombre, la exageración tremendista o sensiblera, el evento casual introducido en el momento perfecto o la psicología maniquea de personajes bueno o malos.

Para denunciar el carácter obsoleto y el ostracismo del realismo español, Bark recurría al tópico de la juventud y contrastaba la vitalidad de los polígrafos germinalistas con el estado «antidiluviano y momificado de los escritores españoles con renombre, que se traduce en una literatura pobre» de espíritu (Bark, 23-VII-1897, pág. 2). De esta manera enjuiciaba nuestro autor las obras de Pereda, Pérez Galdós, Palacio Valdés, Picón, Valera, Pardo Bazán, Munilla y Oller sin por ello dejar de reconocer un potencial creativo en ellos, lamentablemente mal utilizado. Haciendo alusión de nuevo a condicionantes deterministas de raza, escribía Bark al respecto: 
Nadie negará que los citados son artistas dotados de un finísimo sentido poético, que perciben las formas y los colores como cualquier Alejandro Panzani, describen con maravillosa plasticidad los detalles y penetran en la intuición artística del latino en la poesía de la realidad más insignificante, viendo bellezas hasta en el montón de basuras (Bark, 23-VII-1897, pág. 2).

Germinal se convirtió en uno de sus más decididos defensoras del naturalismo de corte socialista, en el que ni siquiera cabía La Desheredada de Galdós, considerada la primera obra naturalista por ser protagonizada por personajes del proletariado. En Germinal ese naturalismo fue considerado trasnochado, asocial y opresor de las masas merced a su falso misticismo y sus escondidos intereses lucrativos. Estos argumentos se acabaron acuñando a modo de tópicos en las páginas de la revista.

En suma, en Germinal la valoración del naturalismo se realizaba bien por oposición, bien a partir del grado de miseria y de los alaridos sociales. Aunque la objetividad y calidad de estas críticas sean cuestionables, nos queda su valor testimonial por configurar el pensamiento de estos grupos revolucionarios, más preocupados por la didáctica que por la estética. Ya lo censuraba Clarín, uno de sus mayores contrincantes, al afirmar que los artistas se habían rebajado a pedagogos, obligando sólo a la razón y no a la imaginación.

Algunos críticos atendieron incluso al estilo y subrayaron la importancia de la objetividad, de la denotación y del estilo llano en la denuncia de las iniquidades sociales (López Lapuya, 1-XI-1897, pág. 10). Sin embargo, en las creaciones de Germinal eran frecuentes las distorsiones de la realidad y la exacerbación de lo feo e inmundo, de modo que muchos textos resultaban en ocasiones panfletos de denuncia social lapidaria. Dichas manipulaciones quedaban encubiertas bajo un pretendido vigor racionalista proporcionado por la inclusión de términos, frases y notas supuestamente científicos. Estos ingredientes positivistas les hacían sentirse dueños de la verdad. Ella era la meta libertaria que les induciría a descubrir de manera lógica las leyes de la perfecta sociedad. Tanto en ensayos como en obras de creación artística, se introdujeron principios científicos simplificados, a veces a modo de pastiche. Se citaban autores y leyes para ser fieles al ideario social y estético socialista. Hablaban del reinado de la razón, del imperio de la ciencia, de la realización de la razón del ideal, entre tantos otros clichés. Del mismo modo, sus creaciones literarias están recargadas de selecciones naturales, de leyes fisiológicas, de electricidades y de mecanicismos, junto a otras odas técnicas, de antropología y de sociología. Todo ello repercutía en la visión anticlerical que ofrecía Germinal ya que era imposible conciliar el determinismo, darwinismo y positivismo científico con los preceptos religiosos de la moral católica. Aquel 
naturalismo hispánico que se quería espiritualista, no era para los germinalistas más que un contrasentido:

¡Cuán cómico nos parece el afán de la devota Señora Pardo Bazán al querer alardear de Naturalismo, cuando el Naturalismo es ante todo y sobre todo, hijo del positivismo determinista, socialista y ateo, porque Dios sólo existe para él bajo la figura de la X desconocida! ¡Cómo ha de ser naturalista en arte quien es católica ferviente! (Werder, C. Von, 24-V-1897, pág. 9).

Bark fue el articulista que más atacó la religiosidad de Emilia Pardo Bazán. Calificaba su naturalismo de desnaturalizado. Los estudios sociológicos, añadía Bark, han de ser ateo-deterministas y socialistas-revolucionarios; por lo que Pardo Bazán no puede ser considerada más que pseudo-naturalista a causa de su catolicismo y sus inclinaciones carlistas. Si Germinal cargó las tintas contra el acientificismo y el clericalismo era en reacción contra los escritores consagrados y la sociedad que dichas figuras representaban. Cierto es que estos escritores habían acomodado el credo artístico naturalista a la coyuntura y el pensamiento español dominante.

A pesar de las airadas polémicas hay que reconocer que entre todos ellos, jóvenes y viejos, no existía un divorcio tan abismal como estos artículos de la prensa dan a entender. A pesar de todas las desavenencias hubo entre ellos algún que otro intercambio e influencia. Obvio es que las autorictas litaeraris no desconocían ni eran impermeables a las tendencias europeas, aun cuando pensasen que sin el adecuado ajuste a España, a la ideología conservadora y a la moral católica, estaban atentaban contra la idiosincrasia de la nacionalidad española. Y ello, sobre todo en prosa extensa, por la capacidad mimética y totalizadora de la novela a la hora de reconstruir objetivamente el mundo social.

\section{El Modernismo}

Realismo, naturalismo, modernismo y otros tantos ismos se barajaban al mismo tiempo y sin que ninguna taxonomía absoluta y exhaustiva resultase plausible. Urbano González Serrano examinaba entre sus artículos aquella situación de indeterminación en la que el mundo de las ideas vivía a la sazón. A su entender dicha indeterminación, generada por entrecruce o seria compenetración de doctrinas, impedía reconocer en cada tendencia «su alcance preciso y su significación exacta. Y, como nuestro intelectual ejemplificaba; quien se apellida socialista defiende por ejemplo soluciones individualistas y recíprocamente» (González Serrano, 22-X-1897, pág. 4). Para González Serrano la convivencia más o menos superpuesta a nivel conceptual de aquellas múltiples tendencias era resultado de la misma naturaleza del pensamiento humano, ya que: 
La extrema inteligencia (el rigor especulativo de la teoría) contradice las condiciones impuestas a la acción, resultando la severidad de lo lógico, paradoja, lógica, porque no surge la vida de la dirección uniforme de un silogismo. Nuestro espíritu, mosaico de sensaciones complicadas, demanda aún en lo especulativo, un compás de espera, que se traduce prácticamente en las obligadas transacciones de la tolerancia (González Serrano, 22-X-1897, pág. 4).

Para comprender la compatibilidad o «transacciones de tolerancia» de este entretejido de corrientes hemos de recordar el carácter subversivo, al menos a nivel teórico que caracterizaba el credo estético de los germinalistas. En los artículos de su revista, el concepto de Modernismo era un término generalizador al igual que ocurría con el membrete de socialismo: una gran bandera que podía abarcar a todos los ismos que mostrasen una actitud enérgica y reformadora. El modernismo entonces tenía un uso extensivo a la pluralidad de corrientes literarias; a veces sinónimo de esteticismo, de simbolismo, de parnasianismo, de prerrafaelismo, de decadentismo; pero, también se aplicaba al naturalismo y al realismo, «ya viejos pero no anticuados», como solía decir Benavente en aquellas épocas (Benavente, 30-VII-1897, pág.1). En fin, era un membrete apto para todas aquellas tendencias generadora que significasen protesta contra los viejos, y como apuntaba Bark, «del espíritu contra la forma y del progreso contra la reacción» (Bark, 1901, pág. 6). Si bien el concepto de Modernismo socialmente quedaba delimitado, no ocurría lo mismo en literatura por la compatibilización de ideas distintas y contradictorias que se permitían, dado el carácter individual y creativo del ejercicio literario, así como las diferentes engendradas en su estudio desde perspectivas diacrónicas o sincrónicas. Tomemos uno de los casos más peculiares, el de Galdós. Se criticaba por su extensa producción, por hacer uso de un Naturalismo moderado; si bien en otras ocasiones se ensalzaba su Electra, simplemente por el anticlericalismo de la obra y el revuelo que originó su estreno. En resumidas cuentas, se denigraba o se ensalzaba a un escritor antiguo, no por la calidad de sus escritos ni por los análisis estéticos de los mismos, sino por su actitud revolucionaria exclusivamente. En estos momentos incipientes, y como bien plantearía Bark en su homónimo libro, modernismo significa, pues, modernización, eclecticismo, heterogeneidad, ambigüedad, aperturismo, regeneración y europeización. Fue la reacción, incluso por parte de los que vivían en la instaurada rutina, ante un fenómeno que sintieron como importante. Estas pequeñas polémicas protagonizadas por Germinal estimularon la circulación de ideas desde el momento en el que la Gente vieja conoció la existencia de tal provocadora corriente.

Por parte de la crítica conservadora fueron frecuentes los testimonios en los que repudiaban a los modernistas por su tipo de vida y por su aspecto 
físico. Un modernista era un melenudo bohemio, un decadente, entre ellos algunos agitadores altruistas, todos inadaptados y marginales. Su denominador común fue siempre el inconformismo y la agresión a la sociedad burguesa. Y, específicamente, a sus dos pilares básicos serán una vez más: la religión y el orden político-social. Todo rechazo de la Gente nueva, canalizado a través del arte, se cifrará en dos direcciones. Algunos adoptarían una lucha abierta desde sus ensayos y sus creaciones a través de la divulgación de una tesis. Se pretendía influir con su línea política en la sociedad, era el adoctrinamiento expreso del receptor: lector o auditorio; siempre en pro del cambio sociopolítico. Para otros, esto caminaba a la par del rechazo de los cánones estéticos establecidos. Se precisaba una renovación estética, cómplice en la reforma y en el rechazo burgués.

En Germinal tenemos una primera prueba de esa doble intención estética y social como factores inherentes de un mismo binomio progresista en el arte. Joaquín Dicenta, representante del naturalismo socialista, era un fiel admirador de D'Annunzio. De hecho, en las páginas de Germinal cometió el error de anticiparse al nombramiento del poeta italiano como diputado, lo cual provocó algunas críticas reaccionarias. Acusaron a los germinalistas de ser falsificadores, aunque el visionario error acabó convirtiéndose en realidad (Dicenta, 17-IX-1897, pág. 2). Resulta interesante el binomio político- artista que el periodista ensalza al presentar al poeta italiano como el defensor de la belleza en las Cámaras e insiste en la conjugación de ambas facetas como prototipo del individuo modernista. El artista tiene que buscar la belleza e inspirarse en la naturaleza. Por ello es lógico que en las circunstancias socio-políticas y económicas del momento, éste tenía que descubrir obligatoriamente lo feo, el dolor y la desventura humana. Lo que D'Annunzio aprehendiese de la realidad, argumentaba Dicenta, se reproduciría gracias a su genio artístico en sus creaciones y, por su compromiso social y político, encontraría una segunda vía de denuncia en la Cámara. La realidad social era la fuente de inspiración, pero se limitaba a la observación de los desgraciados y de los oprimidos, «a la infeliz hija del pueblo, al obrero y al campesino que trabajan como bestias para enriquecer al propietario egoísta y ocioso» y son «víctimas de la explotación, del desprecio, de la ignorancia; pedazos de carne viva triturados para una máquina social que tiene diente de fiera y entrañas de verdugo» (Dicenta, 17-IX-1897, pág. 2)

Puesto que la Belleza, la Verdad y el Bien se encontraban en la naturaleza misma, los críticos de Germinal pensaban que el artista que persiguiese los grandes ideales artísticos descubriría todas las inmundicias y vilezas que el sistema capitalista burgués había generado. Sin duda uno de los casos más 
singulares era el caso de Ramiro de Maeztu, quien publicó poemas parnasianos y de crítica social en la revista. Entre ellos, el más difundido es «A la Venus gigantesca» considerado de incipiente modernismo (Maeztu, 3-VIII-1897, pág. 7). También Zamacois publicaba versos de linaje romántico-becqueriano y no fue considerado modernista por el mero hecho de escribir novelas que reflejan una realidad angustiosa y viva, «un análisis psicológico delicado y profunda reflexión; por su estudio del determinismo, de las leyes de la herencia, de las enfermedades mentales y del medio» (Segura, 10-XII-1897, pág. 11). Sin embargo, de Santiago Rusiñol, calificado de modernista y decadente por su temperamento enfermizo, se ensalzaba el predominio de «un tinte suave, delicado», que es «reflejo de un alma que busca sensaciones nuevas, de un alma que necesita algo más de lo que ofrece la vulgaridad de las gentes» sin que ello suponga una traba para la búsqueda de la verdad y de la realidad social. Rusiñol, uno de los pioneros del arte modernista:

Cuando escribe, vemos a través de las páginas la hermosura del paisaje, formas plásticas, humanas, y cuando pinta, a través del lienzo leemos un sinnúmero de ideas que nos sugiere, y sentimos ante sus lienzos consuelo o pena.

A todas sus brillantes cualidades añade la de ser un psicólogo sutil y delicado. Siente como pocos, sufre con los desgraciados, nos obliga a derramar lágrimas por los infelices Artistas ignorados, por lo que siente un devouément de padre y nos envuelve el espíritu en tristeza al cantar [...] Rusiñol realza, da vida y calor a las cosas más pequeñas, a los detalles más insignificantes; podría llamársele el poeta de los humildes, de las pequeñas tristezas, del ansia de lo desconocido» («Libros Nuevos», 26 -XI- 1897, pág. 9).

$\mathrm{Y}$ así podríamos citar a tantos otros escritores que compartieron y vivieron ambas tendencias o vertientes de una única perspectiva rebelde y de un semejante anhelo de reforma, y que son muestra del agotamiento del naturalismo radical proclamado a ultranza en la revista Germinal, pero también de las vías que el escritor elegía para influir en su público a través de las emociones o de las ideas, lo cual condiciona el tipo de discurso empleado. Con el tiempo, los germinalistas no quisieron prescindir del conocimiento sensible, del universo de las emociones y sentimientos pese a sus preocupaciones sociales, conscientes de que no bastaba la persuasión de la inteligencia para ganar voluntades que se sumasen a la obra social, si de antemano, el sentimiento, el corazón rechazaba la idea.

Liberar las conciencias humanas reclamaba la libertad de pensamiento en el libro, en la tribuna, en el teatro y en el arte, como se indicó antes, ya que eran requisitos previos para la regeneración de España. Esta era la principal tarea a la que contribuían todos los escritores, tanto los que concedían mayor primacía a la atención de los afectos que al intelecto, porque toda obra de arte 
invita a un conocimiento sensible aún en el caso de afiliarse al naturalismo más radical. Si como pensaban los germinalistas la verdad ideal estaba en las ideologías de izquierdas y el artista se adecuaba a las necesidades de su nación, el pueblo se nutriría de las doctrinas que el artista le ofreciese envueltas en una estética más o menos disidente. La transformación en el mundo artístico evolucionaría, pues, de manera paralela a la reforma social, sin escisiones ni polarizaciones. En el mundo de las ideas, cultural y artístico todo es evolución o reacción y ese momento palingenésico es el que reflejaba Germinal al explorar nuevas vías de conocimiento de signo radicalmente distinto al propuesto por la metodología científico experimental.

\section{Del eclecticismo modernista: decadentismo y esteticismo}

La introspección, el conocimiento sensible, el vitalismo e idealismo empezaron a recobrar fuerzas y adeptos al convertirse en mecanismos de compensación de la insatisfacción que el positivismo ya estaba dejando, especialmente en lo referido al significado de la vida y el individuo y sus relaciones sociales, como estudiaremos a continuación. El resurgir del idealismo fue una reacción natural al abuso de la confianza en el cientificismo que no les aportó soluciones inmediatas. El escritor que no encontró nada más allá de aquella visión positivista y fragmentaria de la sociedad burguesa, sondearía forzosamente nuevas vías de conocimiento y credos estéticos. Esto es, el misticismo, el simbolismo y demás ismos que le proporcionarían nuevos significados de la vida más allá de las difíciles realidades sociales.

El concepto de decadencia es probablemente uno de los términos que mejor ponen en evidencia esa transmutación, a primera vista paradójica, del racionalismo científico y ateo hacia un espiritualismo misticista y vitalista que iría ganando terreno a principios del nuevo siglo. Para las mentes germinalistas, la decadencia social y artística corrían parejas, la primera como causa, la segunda como consecuencia de los conflictos y deficiencias políticas, económicas y sociales. El concepto de decadencia, objeto de estudio de filósofos, antropólogos, psicólogos, críticos literarios sería un tema clave en Germinal, con la difusión del pensamiento de Max Nordau, de Paul Bourget y, en particular, de Cesare Lombroso, dada la popularidad que alcanzaron las teorías sobre el delincuente y el criminal al hacerse extensivas al revolucionario político y al artista modernista. Estos autores habían suscitado interesantes polémicas en todos los sectores de la intelectualidad, en los que se etiquetó bajo el nombre de decadencia lo que era «la crisis de un concepto reglamentado y normal de la vida» (Maristany, 1977, pág. 307). Asociándolo al misticismo, el dolor y lo inconsciente, los germinalistas forzarán sus argumentos para que 
dicho concepto encontrase su razón de ser en las mismas tendencias evolutivas de la sociedad y del individuo. Menos superhombres y mesiánicos, nuestros publicistas empezaron a aceptar las limitaciones del conocimiento humano y a aportar razonamientos seudocientíficos con los que explicar lo intangible. Ahora bien, el misticismo ya no se entendía como el resultado de ninguna elucubración idealista, sino como producto de la misma realidad. Según aducía Enrique Maldonado al ofrecer una interpretación socio-política de las teorías de Nordau:

Hay en todo lo que vemos un profundo misterio. Hay en todo lo que vivimos un punzante dolor. El hecho más íntimo de la vida lo constituyen el ensueño y el dolor. De aquí el misticismo. [...] La ciencia son asociaciones sucesivas de ideas, el arte asociaciones sincrónicas. Lo inconsciente no es una fantasía de pesimista, es ya un dato de la ciencia positiva. La irrupción de lo inconsciente en nuestro pensamiento mediante la música de Wagner en su profundo sincronismo, no es una caída, sino una asunción ideal del sentimiento artístico, hijo divino de lo inconsciente, como lo es el sentimiento entero, donde lo inconsciente reina como dios y padre. Por esto la lógica del sentimiento es otra cosa que la dialéctica de la razón (Maldonado, 24-V-1897, pág. 4).

Maldonado, al sintetizar los principales postulados de la teoría del genio de Nordau, expresaba un parcial desacuerdo respecto de la total degeneración mental con la que el ilustre pensador caracterizaba a los autores modernos, en particular, cuando se ponía en tela de juicio la integridad de los autores europeos, "psicóticos degenerados del grupo epiléptico» de gran renombre: Zola, Wagner, Baudelaire, Carlyle, Maeterlinck, entre otros. Artistas, intelectuales y políticos revolucionarios -sobre todo los anarquistas-eran en las páginas de Germinal seres excepcionales que salían de los patrones normales. No obstante, como la normalidad coincidía con la moralidad reglamentada se tendió a sobrevalorar la mediocridad y a marginalizar a estos personajes disidentes, subyacentemente identificados con los delincuentes y criminales. Ello explica que Maldonado pusiese en entredicho la catalogación psicopatológica de tales figuras y las caracterizaciones de las experiencias creativas que Nordau realizaba. Estas últimas se asociaban en su doctrina -al igual que en Lombroso- a estados enfermizos y de desquiciada histeria y epilepsia. A tenor de ello, nuestro periodista intentaría inconscientemente salvar ese divorcio que las doctrinas criminalistas estaban volviendo a socavar entre la ciencia y el arte pues, como acertadamente censuraría Maldonado, los conceptos postulados por Nordau degradaban y desvalorizaban las creaciones de corte misticista: «Lo sublime, que es el infinito de la belleza, es triste... En todo gran dinamismo, en las formas más expansivas y altas de la vida, hay una inestable viva tendencia, que es una viva angustia, un anheloso dolor. La poesía del dolor es 
casi toda la poesía humana. Esta melancolía en el arte conduce a una serenidad clásica» (Maldonado, 24-V-1897, pág. 4). Con el misticismo y el simbolismo surgió el interés por el mundo inconsciente, sucedáneo que reunía los antagónicos términos de un pretendido cientificismo en la forma y el antirracionalismo en el fondo. Su relación con la decadencia reside en esa negación que el hombre sentía al conocer la imposibilidad de dominar su propio ser.

El concepto de degeneración de Paul Bourget, de carácter más psicológico, retuvo también la atención de los germinalistas a raíz de su libro Essais de psychologie contemporaine (1883), traducido en Madrid diez años después. El análisis que Bourget realizó sobre la crisis social e intelectual de su época le condujo a una manifiesta oposición contra todo culto a la ciencia y a la estética naturalista. La decadencia, según Bourget, era producto del individualismo -herencia Nietszche- que dificultaba la adaptación al medio o conjunto social del individuo demasiado fuerte y vigoroso al que la sociedad no había podido domesticar, o sea, constreñir sus instintos y su libertad. De Bourget procede el valor aristocratizante del esteticismo modernista, que se acentuaría poco más tarde cuando ya se generalizó la idea del modernismo decadente. Este era defendido por una nómina de seres raros, exquisitos, hipersensibles, los cuales vivían en un mundo artificial y exclusivamente para el arte. Iniquidades y conflictos sin solventar, revoluciones y repúblicas sin encaminar, promesas y proyectos en el aire acabaron motivando el más absoluto desinterés del compromiso y la contienda políticos. Como sinónimo de Modernista, una vez más, los germinalistas realizarán una interpretación social y ética y harán hincapié en la figura del decadente como individuo representante de la coyuntura nacional del momento. Esta será la perspectiva más divulgada desde Germinal por el paralelismo que siempre se establecía entre la actitud moderna de la gente nueva y la sociedad.

Enrique Maldonado apuntó como una de las causas del decadentismo decimonónico el descubrimiento de las limitaciones del ser humano, por la falta de ideales y de creencias místicas; o sea, por el ateísmo y la tara de conciencia en un estado de degeneración. Esta temática fue tratada por Ibsen, quien al igual que Nordau, lo relacionaba con el problema de la moral. Se pretendía la ruptura con todas las mentiras convencionales. Adoptando a Ibsen como emblema de la regeneración en el arte, en Germinal se ensalzó su teatro, ya que en él se traslada el tradicional conflicto del bien y del mal a su verdadero escenario, es decir, el conflicto de la existencia originado por la colisión trágica entre la vida y el hecho.

El carácter heteróclito y abierto de la revista Germinal se manifestó de nuevo en relación al concepto de decadentismo, término que se consideraría 
en ocasiones peyorativo por la influencia del determinismo ambiental y hereditario sobre las enfermedades mentales y los comportamiento y sentimientos anormales. González Serrano sostenía a este respecto que siempre existe un período de reajuste artístico en los momentos de cambio social. Las orientaciones decadentistas representaban condiciones extremas que eran propulsoras en la ciencia y en el arte y también se materializaban en el desequilibrio individual, la degeneración y el gusto por lo feo, malsano e inmundo:

El romanticismo, que hoy se llama simbolismo, decadentismo, etc. sigue desdeñando por vulgar la criminalidad y la ley, poniendo el ideal en lo anormal y en lo enfermo, execrando la sociedad y la cultura y sustituyendo a la tonicidad del músculo el estímulo nervioso, terreno abonado para el desequilibrio, que toma con Ibsen por dogma la insociabilidad y honor al ser bárbaro como remedio un tanto grotesco de los Manfredo Moor, Ruy Blas, Félix de Montemar y otras creencias románticas (González Serrano, 22-X-1897, pág. 4).

El crítico krausista elaboró asimismo una rudimentaria explicación del desequilibrio neurótico intelectual. Éste era, según él, producto de su aprehensión sensible -emoción o sensación-, anticipada a la imagen de la realidad. Tal fenómeno producía a «surmenage» o sobrexcitación, obligando a prescindir de la capacidad del cerebro humano, sólo recuperable con «tónicos de virilidad de los sentimientos y el vigor de la voluntad».

Por su parte, Alonso y Orera, siguiendo a Ferri, criticó el decadentismo de los estetas, desde perspectivas más sociales y psicológicas -como Bourget-. Dirigía sus ataques hacia toda afirmación del individualismo por resultar negativo para la edificación del pueblo en los grandes valores y sentimientos sociales colectivos (Alonso Orera, 6-VIII-1897, pág. 6). Además, utópicamente sobrevaloraba el arte al erigirlo otra vez en panacea social, como fuente de energía que colaboraría a que las verdades de la antropología y la psiquiatría se difundiesen entre el público. El carácter benefactor del arte era una premisa evidente, puesto que estos germinalistas afirmaban que la causa primera de todos los males físicos e intelectuales que sufrimos no está en la naturaleza sino en las instituciones y organismos sociales, asunto que debían reflejar los personajes literarios. Dicho tratamiento literaturizado fue censurado por parte de la crítica finisecular, que abominaba el falso cientificismo y la superficialidad de los conocimientos de los escritores que equiparaban el valor de sus producciones a las de científicos experimentales.

La exposición más personalizada y exhaustiva de las teorías científicas de la degeneración decadentista fue publicada por José Verdes Montenegro en los primeros números de Germinal. En su opinión, la degeneración era el resultado de la ociosidad de la vida del intelectual. La inacción perturbaba la sensibilidad, lo que provocaba la aparición de los delirios, de las pasiones superfluas 
y de los lujos de la vida desordenada. Los refinamientos espirituales no eran estigmas de degeneración, sino producto de las fuerzas sociales:

como la flor, la creación más delicada de la energía de la planta [...] la existencia de esa aristocracia de la sensibilidad implica, como la de todas las aristocracias, una selección continuada a través de innumerables generaciones; seres y seres ejercitando durante siglos su sensibilidad en el goce de los placeres de la naturaleza y el arte, y perpetuando por herencia la agudeza sensitiva alcanzada (Verdes, 9-VII-1897, pág. 2).

Ahora bien, la existencia de la aristocracia intelectual implicaba, según Verdes, una organización jerarquizada, es decir, un proletariado del cual era parásita. Dicha estratificación social, contraria a la igualdad que pregonaban, era considerada de nimia importancia dada las aportaciones de los intelectuales a la sociedad. Por ello, «lejos de ser tipos degenerados; los intelectuales aparecen como échantillons anticipados de una humanidad superior, que se erigen para la masa amorfa en núcleo de atracción» (Verdes, 9-VII-1897, pág. 3). D' Annunzio, Wilde, Ibsen, Musset representaban, a su entender, los gérmenes del concepto elitista y aristocrático del arte. Recordemos, no obstante, que esa actitud aristocratizante había nacido también del desprecio bohemio de la burguesía y del ensalzamiento que desde la literatura se hacía a todo aquel personaje -como el dandy- que no aceptaba las normas establecidas y se singularizaba por su particular existencia frente a la masa. Bohemia, que nuestros germinalistas, y, sobre todo Bark, condujeron hacia los cauces revolucionarios impregnados heterodoxamente de aquel Naturalismo radical republicano-socialista en teoría. Como escribía Bark, el artista se consideraría un genio, un guía de la humanidad para aquellos que defendían el arte socializante.

Gabriel D' Annunzio encarnaba el modelo de genio en Germinal por ser la síntesis perfecta del artista: el ser un gran esteta y un político activo. El decadentismo y esteticismo en las páginas de Germinal eran socializantes, al igual que aquel postrero naturalismo, aún cuando manipularan subjetivamente la realidad socio-histórica y cultural. La convivencia entre el racionalismo científico y el esteticismo idealista no implicaba más que la toma de conciencia de un vacío que la ciencia, en quien se había confiado tan ciegamente, había engendrado. Germinal, en 1897, no representó más que una etapa fugaz y de transición en el devenir del mundo de las ideas, marcada por el fin de un concepto de decadencia, comúnmente asimilado a degeneración. Poco a poco, decadente ya no fue sinónimo de muerte de una raza o especie, sino la exaltación de lo vital y de lo espontáneo, la afirmación de la sensualidad, la búsqueda del inconsciente, la introducción del esoterismo y del ocultismo, la recuperación de la mística religiosa y la vuelta a la naturalidad medieval y al 
humanitarismo para responder a las grandes cuestiones vitales a las que no se podía responder mediante la objetividad. Los germinalistas divulgaron estas nuevas actitudes y defendieron sus colaboraciones el materialismo progresista a ultranza cuando se enfrentaron con la Gente vieja, portaestandarte del realismo ultramontano español y, a su vez, rechazaron el sistema económico y social nacido de la revolución industrial por haber mercantilizado la literatura, que ellos quisieron democratizar bajo el lema del progreso. Eduardo Zamacois resolvía la aparente contradicción en la que el grupo Germinal podría incurrir al abrazar el racionalismo científico, el materialismo y el sensualismo esteticista (Zamacois, 27-VIII-1897, pág. 9).

Según Zamacois, el desarrollo científico tenía dos poderes: uno moral, otro material; y ambos abarcaban lo humano en los órdenes industrial y social. Sin embargo, sobrevaloraba los progresos de la ciencia en el mundo moral y social en detrimento de los industriales, engarzando con los nuevos valores del socialismo humanista de ascendencia francesa y la doctrina de la moral social de Fouillée y su hijo adoptivo Guyau, que predominó entre los germinalistas y de la que Bark se consideró uno de sus profetas.

En resumidas cuentas, los diferentes matices y rumbos que fue adoptando el mundo de las ideas y el mundo artístico respondían a la evolución de la sociedad. En Germinal, fuese cual fuese la adscripción de cada escritor, desde el defensor del más acérrimo naturalismo radical hasta el simbolista y misticista, todos subsumieron el credo artístico a «lo social», puesto que todos coincidían en adscribir a la Verdad, a la Belleza y a la Justicia el carácter de principios rectores de la futura República Social. En las tribunas de Germinal, la literatura y la estética nueva o moderna, el progreso, el porvenir o la modernidad cristalizaron y se convirtieron en ideas fuerzas, aglutinantes -como la propia ideología- de todas las tendencias estéticas españolas o europeas. Por definirse ante todo como alternativa y afirmarse en la ruptura y la disidencia, Germinal fue forjadora de una heteróclita contra-cultura. La estética germinalista fue compleja, dadas las numerosas respuestas, alianzas, disyuntivas de sus distintas voces, de las diversas mentalidades, valores y actitudes que en su seno reunió; la razón objetiva frente a la razón subjetiva, el positivismo frente al idealismo o una vez más, lo nuevo frente a lo viejo, de modo que los conflictos que la modernidad estética generó son mero reflejo del interés que despertaba.

En Germinal, como en la Modernidad en general, no existía una única estética, sino que varias se entrecruzaban, se compaginaban o incluso se rechazaban. Toda creación que tradujese, recrease o generase sentimientos de crisis, de malestar, pero que persistiese en la búsqueda de nuevos horizontes cabía 
en sus páginas y en Germinal se hizo tanto apología del naturalismo científico, social o radical -para oponerlo al espiritual-, como del decadentismo y del esteticismo. Las corrientes estéticas se acrisolaron en las páginas de Germinal con toda su complejidad, como un modernismo global, ecléctico y tolerante, de modo que la revista hizo las veces de caldo de cultivo, de semillero de ideas y de cánones estéticos. En la diversidad de las creaciones que por sus páginas desfilaron existen también unos objetivos compartidos, unos mínimos comunes o unos puntos de encuentro entre todas las tendencias: la creencia en la función social del arte, en la estrecha relación que en su presente la ideología debía mantener con la estética para canalizar la rebelión y la subversión sin por ello excluir el goce estético.

\section{Bibliografia}

«Germinal», Germinal, 4, 24-V-1897, pág. 1

«Profesión de fe», Germinal, 14, 6-VIII-1897, págs. 1-2.

«Libros Nuevos», Germinal, 30, 26 -XI-1897, pág. 9.

ALONSO Y ORERA, Enrique, «La vuelta de las cigüeñas», Germinal, 14, 6-VIII-1897, págs. 6-7.

BARK, Ernesto (A. de Santaclara), «Orientaciones», Germinal, 2, 7-IV-1899, págs. 4-5.

BARK, Ernesto, «El renacimiento literario», Germinal, 16, 20-VIII-1897, págs. 9-10.

BARK, Ernesto, «Naturalismo español», Germinal, 19, 10-IX-1897, pág. 1.

BARK, Ernesto, Modernismo, Madrid, Biblioteca Germinal, Impr. de Pérez y Compañía, 1901.

BenAVENTE, Jacinto, «Emilio Zola», Germinal, 13, 30-VII-1897, pág.1.

Celma Valero, María Pilar, Literatura y Periodismo en la Revistas del Fin de Siglo. Estudio e Índices (18881907), Madrid, Ensayos Júcar, 1991.

DAVIS, LISA E., «Max Nordau: Degeneración y decadencia en España», Cuadernos Hispanoamericanos, 326-327, Agosto-Septiembre 1977, págs. 307-323.

DiCENTA, Joaquín, «El arte en las Cámaras», Germinal, 20, 17-IX-1897, pág. 2.

Dicenta, José Fernando, La Santa Bohemia, Madrid, Ediciones del Centro, 1976.

FRAGUAS, José, «La educación universitaria», Germinal, 7, 14-VI-1897, págs. 6-7.

FuENTE, Ricardo, De un periodista, Madrid, Mariano Núñez Samper, 1897.

GonZÁlez SERRANO, Urbano, «Los equilibrados y la línea media», Germinal, 25, 22-X-1897, págs. 4-5.

LÓPEZ LAPUYA, Isidoro, «De Bogotá al Atlántico», Germinal, 29, 1- XI-1897, pág. 10.

Maceín, Francisco (Julio Thermidor), «Los órganos», Germinal, 1, 24-III-1899, pág. 4. 
MACEIN, Francisco, «La unidad de ideas», Germinal, 15, 13-VIII-1897, pág. 8.

MAEZTU, Ramiro (Rotuney), «Hombres novísimos», Germinal, 22, 1-X-1897, pág. 8.

MAEZTU, Ramiro de, «A la Venus gigantesca», Germinal, 15, 13-VIII-1897, pág. 7.

MALdONADO, Enrique, «Max Nordau», Germinal, 4, 24-V-1897, pág. 4.

MARISTANY, Luis, El gabinete del doctor Lombroso. Delincuencia y fin de siglo en España, Barcelona, Ed. Anagrama, 1973.

PÉREZ DE LA DEHESA, Rafael, El grupo Germinal, una clave del 98, Madrid, Ed. Taurus, 1970.

RAMOS GASCON, Antonio, «La revista Germinal y los planteamientos estéticos de la Gente nueva», en Rafael Abellán, La crisis de fin de siglo, ideología y literatura, Madrid, Castalia, 1974, págs. 125142.

RoBles EGEA, Antonio, «Republicanismo y socialismo reformista en la crisis del

98: Las ideas del grupo Germinal», Estudios de Historia Social, 2223, 1992, págs. 379-410.

SEGURA, José, «El Punto Negro de Eduardo Zamacois», Germinal, 32, 10-XII-1897, pág. 11.

Thion Soriano-Molla, Dolores, «La Gente Nueva del fin de siglo», Coloquio de la Sociedad Internacional de Hispanistas, Madrid, Castalia, 1999, págs. 425-433.

THION SORIANO-MOLla, Dolores, Ernesto Bark, un propagandista de la Modernidad,

Tesis doctoral, Universidad de Alicante, 1996, parcialmente reproducida en el libro homónimo, Instituto de Cultura Juan Gil Albert, Alicante, 1998.

Verdes Montenegro, José, «Gabriel D’ Annunzio», Germinal, 10, 9-VII-1897, págs. 2-3.

Verdes Montenegro, José, «Los dos dolores», Germinal, 23, 17-XII-1897, pág. 4.

WerTHer, Carlos Von, «Minuta. El primer número», Germinal, 2,7-IV-1899, págs. $5-6$.

ZAMACOIS, Eduardo, «Germinal», Germinal, 1, 30-IV-1897, pág. 2.

ZAMACOIS, Eduardo, «Como se lucha», Germinal, 12, 23-VII-1897, págs. 7-8

ZAMACOIS, Eduardo, «Preliminares», Germinal, 17, 27-VIII-1897, pág. 9.

ZaVala, Iris María, Fin de siglo: Modernismo, 98 y Bohemia, Madrid, Edicusa, 1974.

Fecha de recepción: 18/11/2014

Fecha de aceptación: 09/12/2014 